Joschka Bischoff, Michal Maciejewski, Alexander Sohr

\title{
Analysis of Berlin's taxi services by exploring GPS traces
}

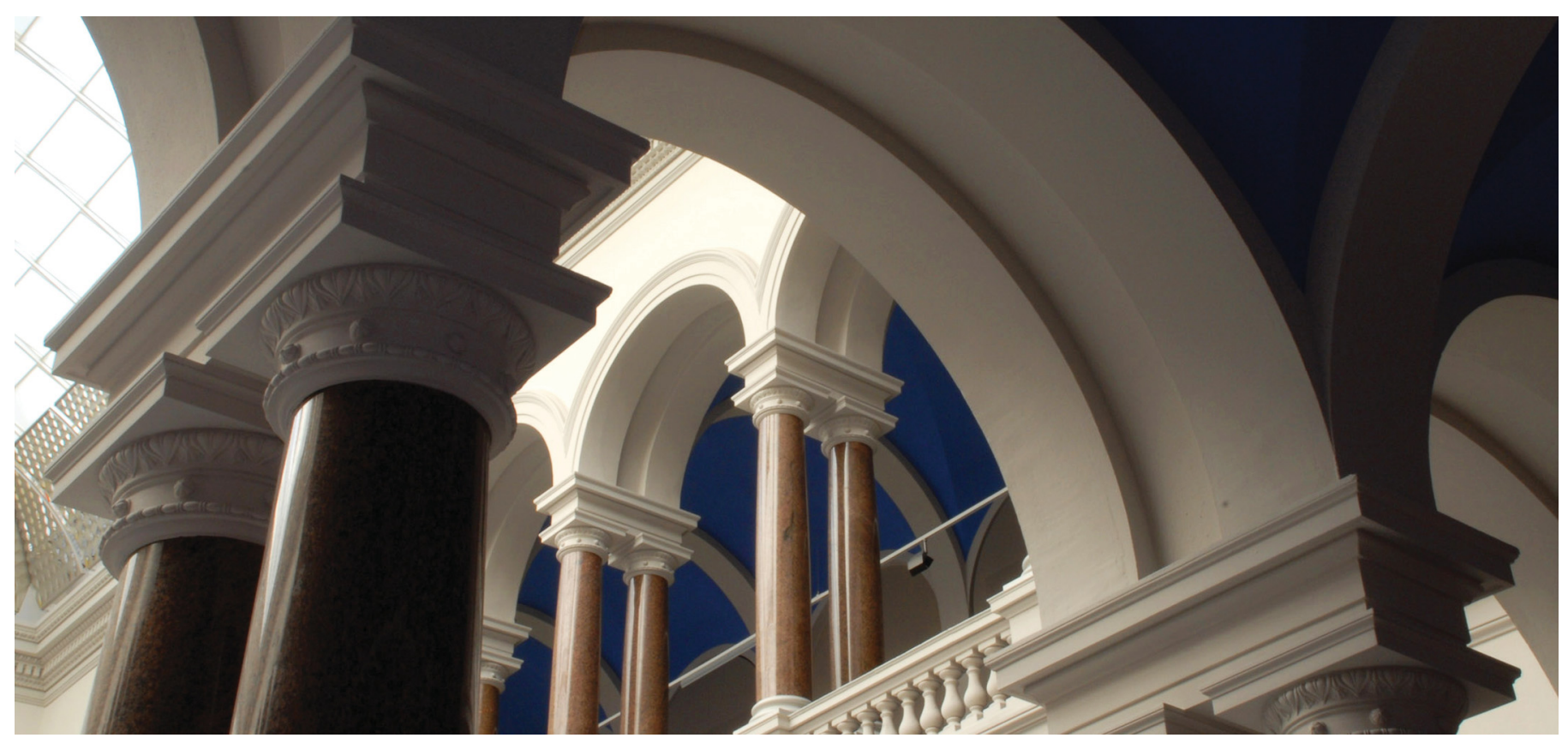

Bischoff, J.; Maciejewski, M.; Sohr, A. (2015). Analysis of Berlin's taxi services by exploring GPS traces. 2015 International Conference on Models and Technologies for Intelligent Transportation Systems (MTITS), 209-215. https://doi.org/10.1109/MTITS.2015.7223258 


\section{Analysis of Berlin's taxi services by exploring GPS traces}

\author{
Joschka Bischoff \\ Technische Universität Berlin \\ Department of Transport Systems Planning \\ and Transport Telematics \\ Berlin, Germany \\ Email: bischoff@vsp.tu-berlin.de
}

\author{
Michal Maciejewski \\ Poznan University of Technology \\ Division of Transport Systems \\ Poznan, Poland \\ Technische Universität Berlin \\ Department of Transport Systems Planning \\ and Transport Telematics \\ Berlin, Germany
}

\author{
Alexander Sohr \\ German Aerospace Center (DLR) \\ Institute for Transport technology \\ Berlin, Germany
}

\begin{abstract}
With current on-board GPS devices a lot of data is being collected while operating taxis. This paper focuses on analysing travel behaviour and vehicle supply of the Berlin taxi market using floating car data (FCD) for one week each in 2013 and 2014. The data suggests that there is generally a demand peak on workday mornings and a second peak over a longer time in the afternoon. On weekends, the demand peaks shift towards the night. On the supply side, drivers seem to adapt to the demand peaks very efficiently, with fewer taxis being available at times of low demand, such as during midday. A spatial analysis shows that most taxi trips take place either within the city centre or from/to Tegel Airport, the city's largest single origin and destination. Drivers spend a large amount of their work time on waiting for customers and the taxi rank at Tegel Airport is the most popular one.
\end{abstract}

Keywords-Taxi Berlin, floating car data, FCD, taxi demand, taxi supply, Tegel Airport

\section{INTRODUCTION}

Although taxi services are one of the core elements of urban transport systems, the scientific focus on them had been limited until recent developments in information and communications technology (ICT). Nowadays taxis equipped with mobile devices may be monitored and managed remotely. This has opened up a broad range of new services, such as shared taxis, Uber and similar, or even autonomous taxis in the future. Due to the onboard devices a lot of data is being collected while operating taxis. These data make up a very extensive source of information on urban traffic that can be used, for example, to estimate time-dependent travel times. They can also provide an insight into the travel behaviour, which is the subject of this paper.

The paper deals specifically with taxis in Berlin. Being Germany's capital and largest city, the city forms a hotspot for business, public services and tourists alike. In combination with a comparingly low percentage of private car ownership among its inhabitants, the city is an interesting location for taxi businesses.

\section{RELATED WORK}

There have been several studies on analysing taxi data all over the world, most of them focusing on the Asian market. In Europe, taxi trips in Lisbon were analysed to explore relationships between origins and destinations of taxi trips and predict taxi demand [1]. The results of such analyses may be used to improve the quality of taxi dispatch. In Hangzhou the trajectories of 5500 taxis were analysed to determine taxi drivers' best strategies to pick up passengers at a given time and location [2]. A study in Shenzhen explored taxidrivers' operation patterns with the focus on differences between the behaviour of top drivers and of ordinary ones [3]. For Bejing, a recommendation system for taxi drivers and passengers was implemented to help them in efficient mutual finding [4]. In Shanghai, spatio-temporal profitability maps were introduced to help taxi drivers with reducing cruising miles [5]. Similarly, prediction of taxi demand hotspots has been studied for Taipei [6] and for Hangzhou [7].

Taxi trajectories have been used for estimating urban link travel times, e.g. in Manhattan [8], and for time-dependent path finding. In Berlin, fleet travel times were reduced by measuring real-time travel times using floating car data from taxis [9]. Similarly, taxi trajectories were used to devised shortest path searching algorithms for Wuhan [10] and Bejing [11]. In Bejing, a parallel algorithm to process massive taxi traces for detecting traffic hot spots was proposed [12].

Taxi trajectories have been used also in many other areas. One approach is to use them to detect flawed urban planning [13], another one to determine land use by analysing taxi pick-ups and drop-offs [14]. Also spatial interaction models were calibrated using taxi trajectories [15].

\section{DATA}

In December 2012, around 8000 taxis were licensed to operate in the city. Those vehicles were operated by around 18000 taxi drivers which were organised in 3000 taxi 
companies. Of these companies, 2368 operate only one vehicle each, 206 companies have two vehicles and 427 three or more taxicabs [16]. Metered taxi fares are strictly regulated in Berlin. Market access for new operators comes only with technical entrance barriers, but, in contrast to many other countries, there is no limitation in the amount of available taxi licenses.

The data used in the study is based on historical trajectories of taxicabs managed by Taxi Berlin, Berlin's largest taxi association dispatching roughly $70 \%$ of the city's taxi fleet. Additionally a small fleet of about 30 taxis in Potsdam is connected to the system. The GPS position of each taxi is logged every 30-60 seconds depending of its current status. If the cab has a customer on board, the position is sent once in a minute, because it is not available for dispatching purposes and thus its position is less important for the taxi association. Consequently empty vehicles are tracked more frequently to warrant an allocation of the closest vehicle to new customers. Overall, around 2 million GPS positions are recorded per day. This way, a database of historical GPS traces arises. Each entry contains the following fields:

- temporary taxi identifier (ID) - changing several times a day to assure that taxi drivers' privacy is not compromised (Taxi Berlin is an association and not the company hiring taxi drivers)

- coordinates - geographical location

- time - time the record is logged

- $\quad$ status - one of ten different statuses such as driving to a customer, driving with a customer, waiting for a customer, waiting at a taxi rank, etc.

To build trajectories from raw GPS positions, first some basic plausibility checks are performed. These include:

- the taxi's location

- the entry's uniqueness

- improbable location variations

- a validation of the currently driven speed

In the next step, based on the status information, the start and the end of the trajectories is determined. These trajectories are then map matched and travel times within the city can be derived, which is the main purpose of data collection both for commercial and research reasons [17].

Extraction of taxi demand and spatiotemporal supply distribution from the GPS traces results in the following data:

- hourly zone-based ${ }^{1}$ OD-matrices based on the vehicles' statuses

- the amount of taxicabs per status and zone in fiveminute intervals

\footnotetext{
${ }^{1}$ For Berlin, zones are determined by LORs http://www.stadtentwicklung. berlin.de/planen/basisdaten_stadtentwicklung/lor/, for the surrounding areas according to municipalities
}

- the duration and time stamp of each temporary taxi ID with the relevant vehicle status

There are, however, some limitations related to the properties of the trajectory database. First of all, due to the automatic anonymisation (IDs are not fixed over a day), it is not possible to provide full daily trajectories of individual taxi drivers. Secondly, data sets only include vehicles that are associated within Taxi Berlin. Consequently, it does not include taxi drivers which exclusively pick up passengers at taxi ranks or by roaming through streets. These drivers supposingly constitute for a large share of taxi supply at places with a high likelihood for on-the-spot trips, e.g. airports or night clubs. Last but not least, recent estimation suggest that up to $40 \%$ of all taxi trips in Berlin are black-market rides without proper fiscal records [18]. This may result in errors while analysing status data, as drivers will set their status to 'available' when, in fact, they have a customer on board. Hence, not all trips could be tracked correctly for this paper. Thus, the demand and amount of taxi trips may in fact be higher.

Two weekly data sets of GPS traces are used in this study. The first set dates from 15 to 21 April 2013, whereas the second includes data from 7 to 13 April 2014. The demand for taxi trips is depending on several outer impacts such as holidays, availability of transport alternatives and weather conditions. Overall, these outer impacts were rather similar in both weeks monitored in this study: Both weeks lie outside major German holiday periods, however, during the week in 2014, the federal states Niedersachsen and Bremen had school holidays. In neither week any large-scale event took place. Rapid public transit was running without any planned major interruptions during both time periods. For the week in 2013, the outside temperatures were overall higher than 2014. In neither week high rainfall had been measured.

\section{FINDINGS}

\section{A. Time-based taxi demand and supply}

A detailed distribution of taxi supply (the number of taxis logged into the system) and demand (the number of requests submitted per hour) over a week are presented in Fig. 1 for 2013 and Fig. 2 for 2014. For the demand side, the following applies:

- Taxi demand during weekdays (Monday morning Friday morning) follows a clear pattern with a major peak around 9 am and a smaller one during the afternoon.

- Friday is demand-wise the busiest day, with a somewhat smaller morning peak followed by a high demand during evening and night hours.

- The weekly peak-hour for taxi demand is Saturday night.

- Besides Friday and Saturday night, the demand for taxi services during weekends is low. 


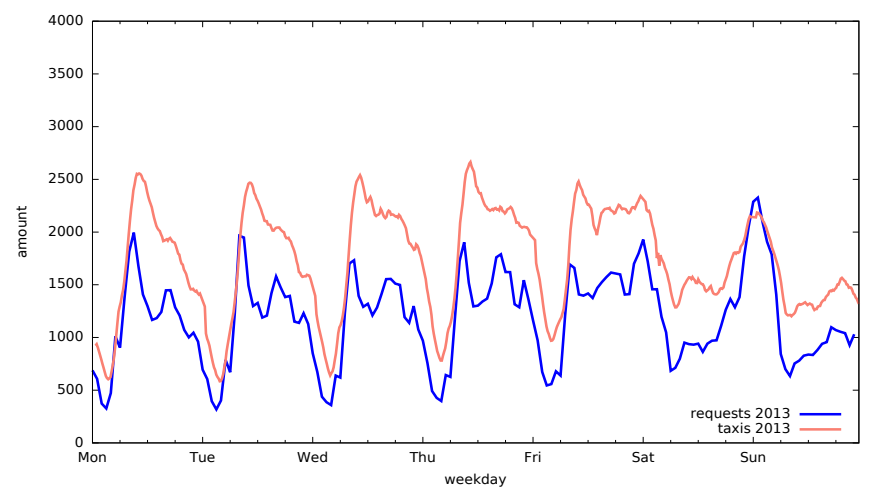

Fig. 1. Request submissions per hour and active taxis (2013)

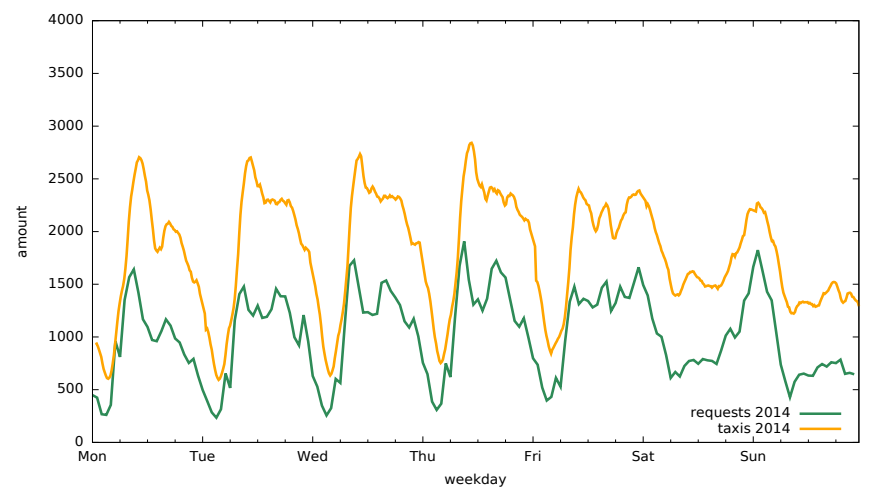

Fig. 2. Request submissions per hour and active taxis (2014)

As both figures show, the supply adapts surprisingly well to the demand. Peaks in demand are generally matched by a larger supply. For most of the time, the number of available taxis is higher than of hourly request submissions, which means that every taxi serves less than one request per hour. Saturday night in 2013 is the only exception to this with less taxis being in service than requests per hour.

Overall, the week in 2013 has a higher demand for taxi trips, with 198445 trips in total versus 169651 trips for the week in 2014. This is mainly due to a higher demand during Saturday night. However, the demand in 2014 is lower at most other times as well (see Fig. 3) On the other hand, the amount of active vehicles is higher during most times in 2014 (see Fig. 4). This goes in line with the trend of the steadily growing taxi fleet in Berlin over the last years[16] .

\section{B. Trip distances}

The average trip distances, calculated as the beeline distance between the zone centres, are at most weekday hours between four and five kilometres (Fig. 5). However, the weekday mornings (5-7 am), with average distances of six to eight kilometres, form a notable exception. The day with the highest average trip distance is, on the other hand, Sunday. Overall, average trip distance is similar for 2013 and 2014. As to the distribution of trip distances (cf. Fig. 6), there are

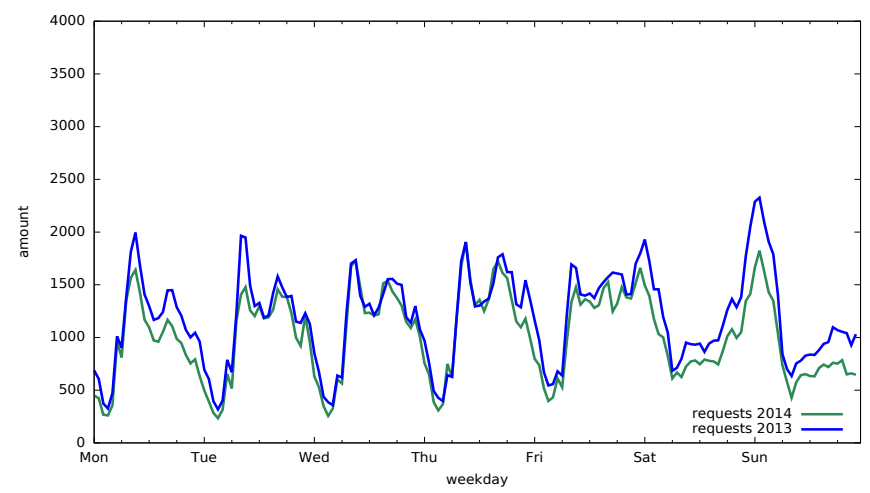

Fig. 3. Request submissions per hour (2013 and 2014)

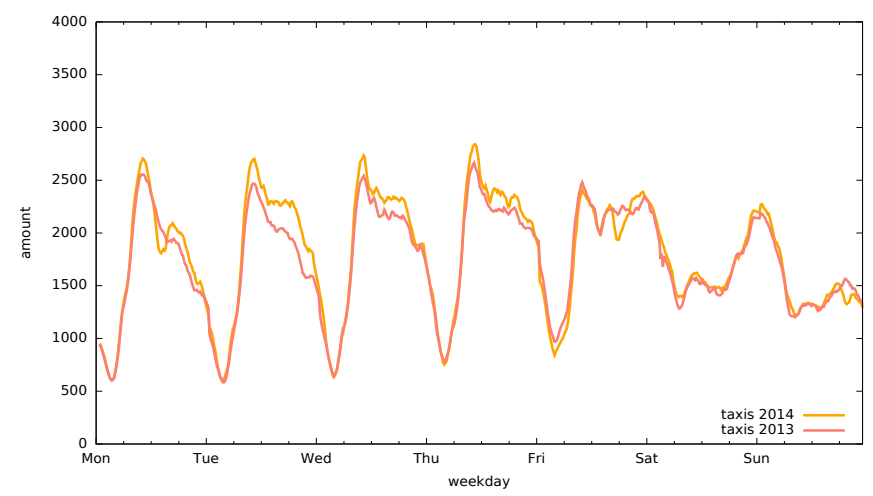

Fig. 4. Active taxis (2013 and 2014)

few trips of less than two kilometre beeline distance, whereas a trip distance between two and three kilometres is the most common. Longer distances are less and less likely - not even ten percent of all trips are ten kilometres or longer.

\section{Location-based taxi demand}

Origins and destinations of taxi trips are generally spread all over the city. The majority commences and ends within the city centre (defined as the inner railway circle), as Figure 7 shows. The data suggest that there are more trips from the city centre to the outside than vice versa, though this could be due to the fact that many trips from Tegel Airport are made by taxis that are not affiliated with a radio-cab operator ${ }^{2}$ and most trips from Schönefeld airport are made by taxis which are registered in a surrounding parish rather than Berlin. Both types of taxis are not a part of the data set.

Fig. 8 shows the overall top 100 OD-relations and the attractiveness, measured as the number of incoming trips, of zones during the week in 2013. Notable are the following points:

\footnotetext{
${ }^{2}$ For unaffiliated drivers it is easier to wait for passengers at the airport or other high-demand locations than to search for them cruising through the city.
} 


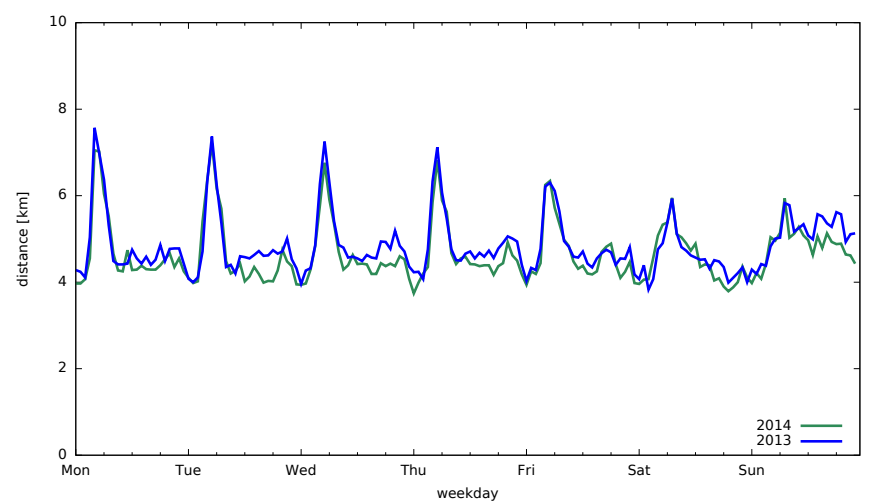

Fig. 5. Average beeline trip distance at different times (2013 and 2014)

- Trips between the city centre and Tegel Airport make up for most of the top OD relations and is hence also the most sought-after destination.

- Other frequently used relations are almost exclusively within the city centre, with one notable exception (see below).

- In general, the central zones are more likely to be destinations of taxi trips. Yet the picture is rather diverse with some outskirts also being a popular destination.

- The city's second airport, Schönefeld, is neither a destination nor an origin in the top 100 relations.

The notable exception is one relation are trips from southern Pankow to the northern part of the district, with a total of 106 trips. In the opposite direction only 44 trips have been measured. The relation seems unusual, but can be explained by construction works on the tram line M1 which connects the area during the week monitored. Especially in the northbound direction the offered bus replacement may not have provided

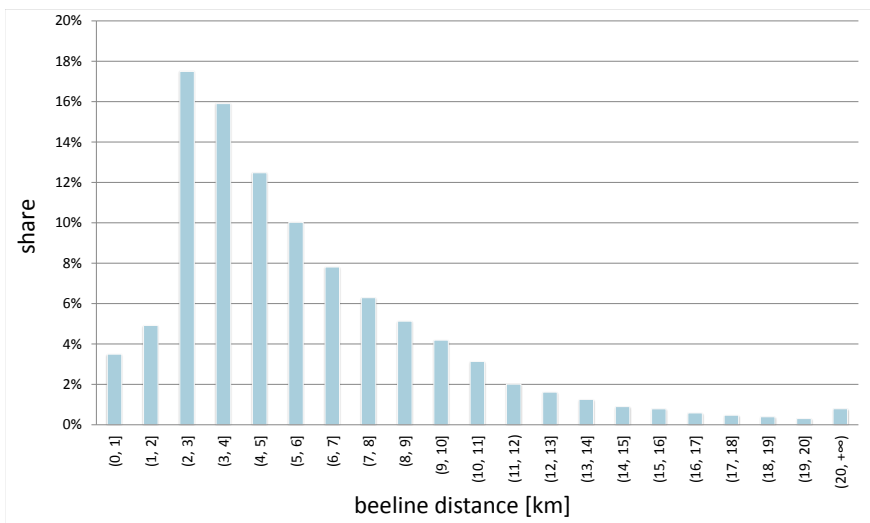

Fig. 6. Taxi trip distance distribution (2013 and 2014)

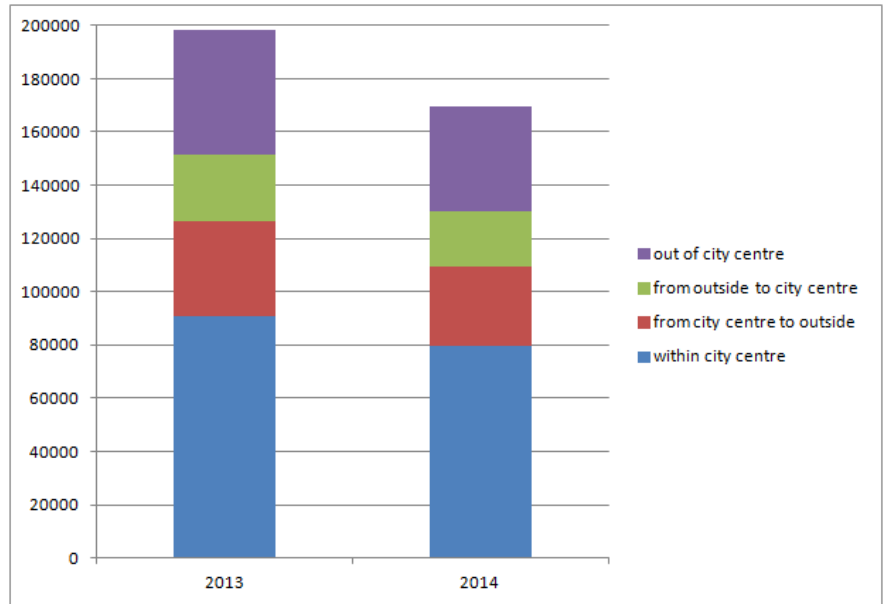

Fig. 7. Taxi trip allocation within the city (2013 and 2014)

the expected level of service, for example, due to lost connections. This may have lead to an increase in taxi demand.

Points of special interest are often a destination for taxi trips. These include train stations, the fair grounds and major event locations (the airport-related taxi traffic is analysed in Section IV-D). Trips to a selection of such locations are displayed in Figure 9. Of all train stations with regular longdistance connections, Hauptbahnhof (Central Station) has the biggest attraction for taxi traffic, with more than ten weekly trips from almost any zone in the city centre. Ostbahnhof (in the east) and Spandau (in the far west) stations attract taxi business to a much lesser degree and mainly on a district-wide level. Some zones notably have an equally high attraction to both Hauptbahnhof and Ostbahnhof. Finally, Südkreuz (in the south) and Gesundbrunnen (in the north) are almost exclusively destinations for short-range taxi trips. The fair ground has a

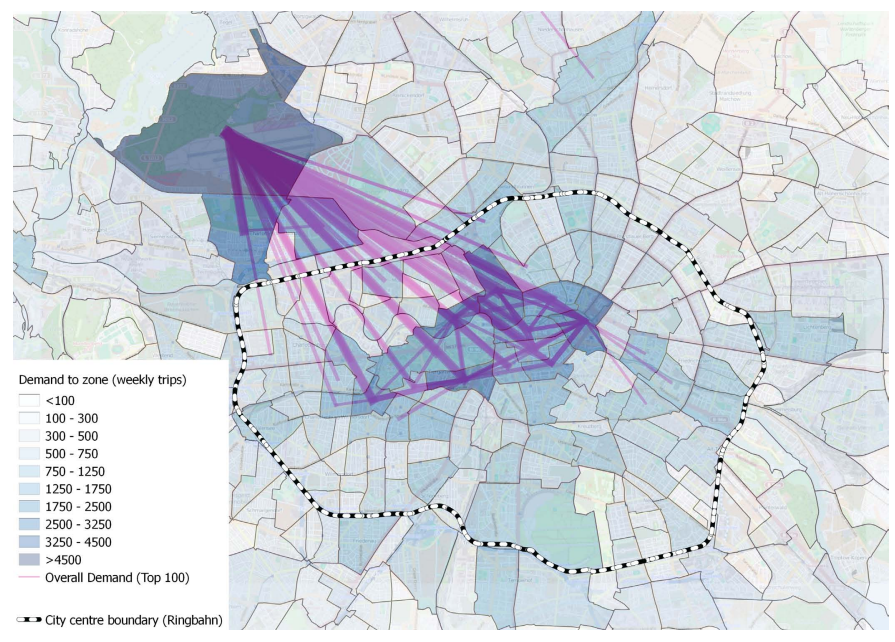

Fig. 8. Number of incoming taxi trips per zone (blue colour scale) and the top 100 OD-relations (variable-width purple lines) for the week in 2013. Map source: OpenStreetMap contributors. 


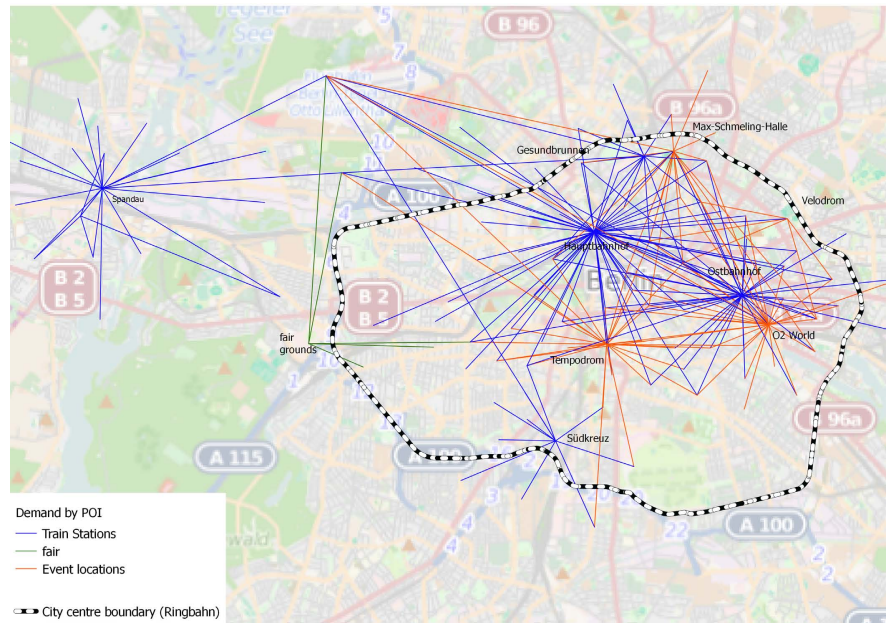

Fig. 9. Selection of Berlin's points of interest and the incoming taxi flows of at least 10 trips per week (2013)

Map source: OpenStreetMap contributors.

certain amount of trips from Tegel Airport and the western city centre around Kurfüstendamm. Since there was no bigger trade fair, this seems reasonable. For event locations, no clear pattern emerges. Taxi trips to zones near them are generally short-distance trips from within the city centre, with a notable exception around the Tempodrom. However the likelihood of travelling by taxi to a mass event is also depending on the actual event itself.

\section{Airports}

As already seen in the previous analyses, taxi trips to and from Tegel and Schönefeld airports constitute for a large amount of all taxi trips in Berlin. The following numbers are once more based on the week in April 2013. The amount of trips to Tegel is much higher (14 144 trips) due to its proximity to the city, the lack of a direct rail link and higher air passenger numbers. To Schönefeld, only 1938 trips took place. On the other hand, with $7.48 \mathrm{~km}$, the average beeline trip distance to Tegel is only half as long compared to Schönefeld (14.27 km). As Fig. 10 shows, origins for trips to the airports are similar in the city centre, but tend to differ in the outskirts. One possible interpretation would be that passengers departing in southern parts of the city would rather use a taxi to Schönefeld than to Tegel and vice versa. Thus the likelihood of taxi usages decreases with a growing distance from the airport.

\section{E. Symmetries in taxi demand}

For taxi dispatching, one of the more important questions is, whether taxi demand between different city areas is symmetric and whether trips in one direction occur at different times than in the other direction. In general, demand for taxi trips is rather symmetric between zones. The most notable exceptions may be explained by the aforementioned reduced share of Taxi Berlin in serving trips originating at both airports. Fig. 11 provides an overview. The asymmetry is best illustrated by taxi flows incoming to and outgoing from Tegel Airport.

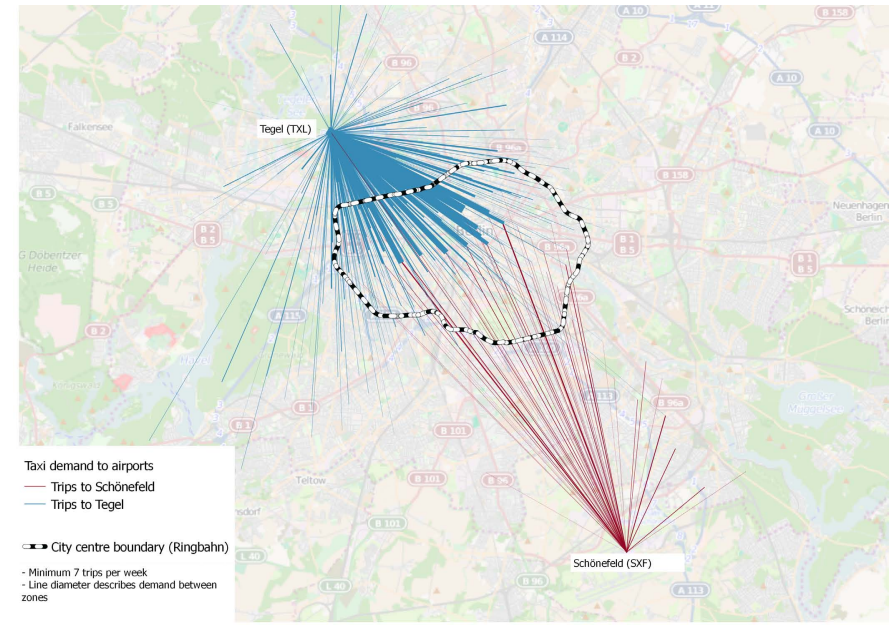

Fig. 10. Taxi flows incoming to Berlin's airports (2013). Map source: OpenStreetMap contributors.

\section{F. Idle taxi distribution}

Within Berlin, there are roughly 400 taxi ranks, which is where most taxi drivers gather. Figure 12 provides an overview of rank locations and the average number of idle taxis in each zone at each moment during the week in 2014. Tegel Airport attracts overall most vehicles. Drivers accept waiting times of up to several hours at this rank. One reason might be that the following ride has the chance of being especially rewarding. Furthermore, the general infrastructure for waiting taxi drivers is rather good here, so some drivers might prefer it over other ranks.

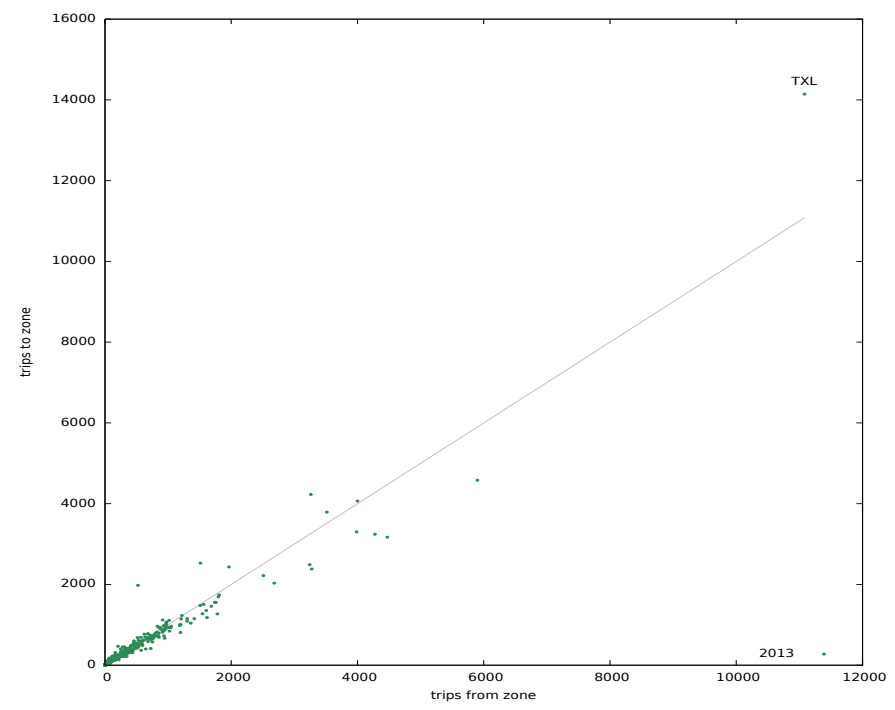

Fig. 11. Outgoing vs. incoming taxi flows by zone for the week in 2013 


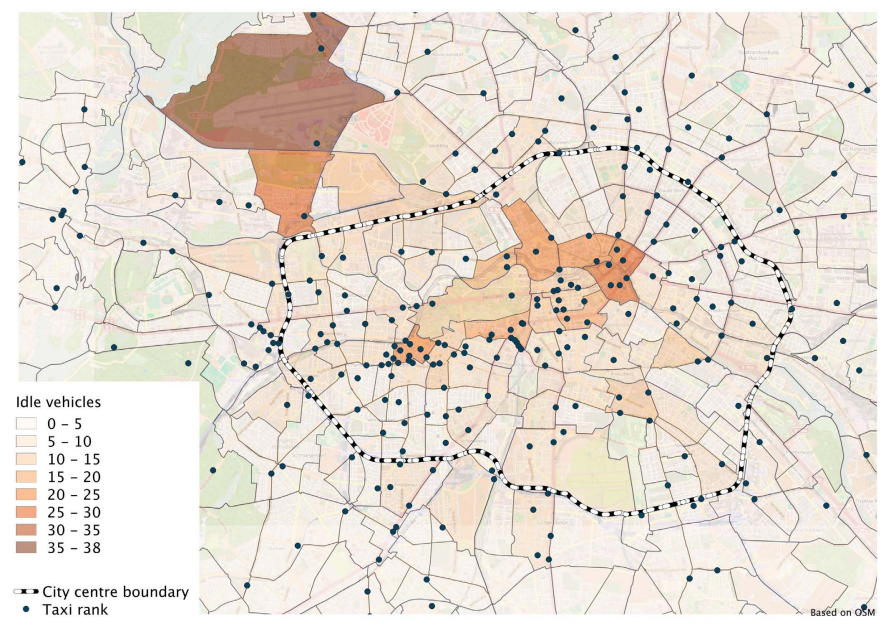

Fig. 12. Average amount of idle taxis per zone (2014)

\section{G. Taxi dispatching statistics}

An illustration of the average daily occupation of taxi drivers is presented in Tab. I, where all types of the taxi statuses (see Sec. III) have been aggregated into the following four main categories:

- to-customer - driving to and waiting for a customer

- with-customer - driving with a customer

- $\quad$ at-rank - standing at a taxi rank

- $\quad$ outside-rank - idle but not at a rank, e.g. cruising or returning to a rank

First of all, one can clearly see that Taxi Berlin typically operates under low load and taxis remain idle for over $70 \%$ of time. Secondly, the similar share of to-customer and idle categories proves that after serving a customer, drivers tend to return to one of the nearest taxi ranks and thus do not have only one favourite rank (the triangle inequality does not hold, i.e. to-customer + outside-rank $<$ with-customer $)$. However, due to the aforementioned anonymisation of the GPS traces, it is impossible to be exact on the daily mileage of taxicabs and drivers, or to find out whether drivers have a set of their own favourite taxi ranks distributed over the city or they do not have any preference at all. Last but not least, the high share of the at-rank category may result from not reporting all trips in order to avoid paying fees or taxes (see Section III).

\section{CONCLUSION}

Berlin's taxi traffic under usual demand conditions is in general relaxed. The supply adjusts to the demand very well

TABLE I. TAXI DRIVER ACTIVITIES AND THEIR TIME SHARE (2014)

\begin{tabular}{cc}
\hline Activity & Time share [\%] \\
\hline to customer & 6.7 \\
with customer & 21.8 \\
at rank & 62.7 \\
outside rank & 8.8 \\
\hline
\end{tabular}

with biggest demand peaks being weekday mornings and weekend nights. These peak patterns are repeating both in 2013 and 2014. The top single origin and destination is clearly Tegel Airport, most trips however take place within the city centre. A correlation between taxi demand and interruptions in public transit is noticeable in at least one case.

\section{ACKNOWLEDGMENT}

The authors would like to thank the Einstein foundation for co-funding this paper and TAXI Berlin TZB GmbH for data provision.

\section{REFERENCES}

[1] M. Veloso, S. Phithakkitnukoon, and C. Bento, "Sensing urban mobility with taxi flow," in Proceedings of the 3rd ACM SIGSPATIAL International Workshop on Location-Based Social Networks, ser. LBSN '11. New York, NY, USA: ACM, 2011, pp. 41-44. [Online]. Available: http://doi.acm.org/10.1145/2063212.2063215

[2] B. Li, D. Zhang, L. Sun, and C. Chen, "Hunting or waiting? discovering passenger-finding strategies from a large-scale real-world taxi dataset," in 8th IEE International Workshop on Managing Ubiquitous Communications and Services, 2011.

[3] L. Liu, C. Andris, and C. Ratti, "Uncovering cabdrivers behavior patterns from their digital traces," Computers, Environment and Urban Systems, vol. 34, no. 6, pp. 541-548, 2010.

[4] J. Yuan, Y. Zheng, L. Zhang, X. Xie, and G. Sun, "Where to find my next passenger," in Proceedings of the 13th international conference on Ubiquitous computing. ACM, 2011, pp. 109-118.

[5] J. Powell, Y. Huang, F. Bastani, and M. Ji, "Towards reducing taxicab cruising time using spatio-temporal profitability maps," Advances in Spatial and Temporal Databases, pp. 242-260, 2011.

[6] H.-w. Chang, Y.-c. Tai, H. Chen, J. Y.-j. Hsu, and C. Kuo, "itaxi: Context-aware taxi demand hotspots prediction using ontology and data mining approaches," in Proceedings of the 13th Conference on Artificial Intelligence and Applications (TAAI 2008), 2008.

[7] X. Li, G. Pan, Z. Wu, G. Qi, S. Li, D. Zhang, W. Zhang, and Z. Wang, "Prediction of urban human mobility using large-scale taxi traces and its applications," Frontiers of Computer Science, vol. 6, no. 1, pp. 111-121, 2012.

[8] X. Zhan, S. Hasan, S. V. Ukkusuri, and C. Kamga, "Urban link travel time estimation using large-scale taxi data with partial information," Transportation Research Part C: Emerging Technologies, vol. 33, no. 0, pp. $37-49$, 2013. [Online]. Available: http: //www.sciencedirect.com/science/article/pii/S0968090X13000740

[9] R. Ebendt, A. Sohr, L. Touko-Tcheumadjeu, and P. Wagner, "Dynamische Neuplanung der Touren von Express Trucks unter Einbeziehung einer FCD-basierten Verkehrslage," Multikonferenz Wirtschaftsinformatik, 2012.

[10] Q. Li, Z. Zeng, T. Zhang, J. Li, and Z. Wu, "Path-finding through flexible hierarchical road networks: An experiential approach using taxi trajectory data," International Journal of Applied Earth Observation and Geoinformation, vol. 13, no. 1, pp. 110 - 119, 2011. [Online]. Available: http://www.sciencedirect.com/science/article/pii/S0303243410000930

[11] J. Yuan, Y. Zheng, C. Zhang, W. Xie, X. Xie, G. Sun, and Y. Huang, "Tdrive: driving directions based on taxi trajectories," in Proceedings of the 18th SIGSPATIAL International Conference on Advances in Geographic Information Systems. ACM, 2010, pp. 99-108.

[12] Z. GUI and H. YU, "Mining traffic hot spots from massive taxi trace," Journal of Computational Information Systems, vol. 10, no. 7, pp. 27512760, 2014.

[13] Y. Zheng, Y. Liu, J. Yuan, and X. Xie, "Urban computing with taxicabs," in Proceedings of the 13th international conference on Ubiquitous computing. ACM, 2011, pp. 89-98. 
2015 Models and Technologies for Intelligent Transportation Systems (MT-ITS)

3-5. June 2015. Budapest, Hungary

[14] Y. Liu, F. Wang, Y. Xiao, and S. Gao, "Urban land uses and traffic source-sink areas: Evidence from GPS-enabled taxi data in Shanghai," Landscape and Urban Planning, vol. 106, no. 1, pp. 73 - 87, 2012. [Online]. Available: http://www.sciencedirect.com/science/ article/pii/S0169204612000631

[15] Y. Yue, H. dong Wang, B. Hu, Q. quan Li, Y. guang Li, and A. G. Yeh, "Exploratory calibration of a spatial interaction model using taxi GPS trajectories," Computers, Environment and Urban Systems, vol. 36, no. 2, pp. 140 - 153, 2012, special Issue: Geoinformatics 2010. [Online]. Available: http://www.sciencedirect.com/science/article/ pii/S0198971511000901
[16] BZP - Deutscher Taxi- und Mietwagenverband e.V., "Zahlen über den Taxi- und Mietwagenverkehr 2013/2014," 2014. [Online]. Available: http://www.bzp.org/Content/SERVICE/Geschaeftsbericht/index. php?Z_highmain=6\&Z_highsub=2\&Z_highsubsub=0

[17] E. Brockfeld, A. Sohr, and R. Ebendt, "Validation of a Taxi-FCD system by GPS -testdrives," 2014, german Aerospace Center, Institute of Transport Systems. [Online]. Available: http://elib.dlr.de/66060/1/ TP014-4.pdf

[18] S. Sauer, "Wie der Mindestlohn das Taxi-Gewerbe veraendert," Berliner Zeitung, 2014. [Online]. Available: http://bit.ly/16MeUBH 